\title{
Incidence of Myclobutanil- and Kresoxim-Methyl-Insensitive Isolates of Venturia inaequalis in Quebec Orchards
}

\author{
T. Jobin and O. Carisse, Agriculture and Agri-Food Canada, 430 Gouin Boulevard, St-Jean-sur-Richelieu, Quebec, \\ J3B 3E6, Canada
}

\begin{abstract}
Jobin, T., and Carisse, O. 2007. Incidence of myclobutanil- and kresoxim-methyl-insensitive isolates of Venturia inaequalis in Quebec orchards. Plant Dis. 91:1351-1358.

Sensitivity of baseline and exposed populations of Venturia inaequalis to myclobutanil and to kresoxim-methyl were evaluated in vitro. For myclobutanil, the population was constructed with 238 monoconidial isolates of $V$. inaequalis collected from 48 orchards. For kresoxim-methyl, the population was constructed with 251 monoconidial isolates collected from 49 orchards. Baseline populations were constructed with 34 and 29 monoconidial isolates collected from apple trees that had never been treated for myclobutanil and kresoxim-methyl, respectively. Sensitivity to fungicides was evaluated based on $50 \%$ effective dose $\left(\mathrm{ED}_{50}\right)$ values. The $V$. inaequalis population that was not exposed to myclobutanil had a baseline sensitivity (mean $\mathrm{ED}_{50}$ ) of $0.064 \mu \mathrm{g} / \mathrm{ml}$ and showed a lognormal distribution. The $V$. inaequalis population constructed with isolates from commercial orchards had a mean $\mathrm{ED}_{50}$ of $2.600 \mu \mathrm{g} / \mathrm{ml}$, which was significantly higher than the baseline sensitivity. The distribution of $\mathrm{ED}_{50}$ values did not follow a lognormal distribution. In response to declining levels of scab control with myclobutanil and other sterol demethylation inhibitor fungicides (DMIs), three orchards were more deeply investigated. The mean $\mathrm{ED}_{50}$ values were $1.618(n=23), 3.079(n=29)$, and $1.500 \mu \mathrm{g} / \mathrm{ml}(n=20)$ in orchards one, two, and three, respectively. Resistant isolates, according to criteria set by other studies, accounted for 39, 76 , and $85 \%$ of the isolates tested. The V. inaequalis population that had never been exposed to kresoxim-methyl had a baseline sensitivity (mean $\mathrm{ED}_{50}$ ) of $0.092 \mu \mathrm{g} / \mathrm{ml}$ and showed a lognormal distribution. The $V$. inaequalis population constructed with isolates from commercial orchards had a mean $\mathrm{ED}_{50}$ of $6.093 \mu \mathrm{g} / \mathrm{ml}$, which was significantly higher than the baseline sensitivity. The distribution of $\mathrm{ED}_{50}$ values followed a lognormal distribution. However, when a subsample of isolates was retested for their sensitivity to kresoxim-methyl with the addition of salicylhydroxamic acid (an inhibitor of alternative oxidase) at $100 \mu \mathrm{g} / \mathrm{ml}$ to the growth medium, more than $98 \%$ inhibition was observed for all isolates. The results from in vitro tests showed a high level of resistance to myclobutanil and a low level of resistance to kresoxim-methyl, suggesting that the use of myclobutanil and DMIs should be discontinued or significantly reduced before practical resistance is reached.
\end{abstract}

In today's agriculture, fungicide resistance is a common problem worldwide, regardless of the area or the crop. Apple scab, caused by the ascomycete Venturia inaequalis (Cooke) G. Winter, is the main fungal disease that affects orchards in the province of Quebec, Canada, and fungicide resistance is a concern to growers. Several fungicides are registered for use on apple to control apple scab, including captan (Captan Supra 80 WDG and Maestro 80 DF), EBDC (Dithane DG, Manzate 200DF, Penncozed 75DF, and Polyram DF), thiophanate-methyl (Senator 70), dodine (Equal 65W), myclobutanil (Nova 40W), flusilazole (Nustar), cyprodinil (Vangard), kresoxim-methyl (Sovran 50GS), and trifloxystrobine (Flint 50DG).

Corresponding author: O. Carisse

E-mail: carisseo@agr.gc.ca

Accepted for publication 31 May 2007.

doi:10.1094/PDIS-91-10-1351

(c) 2007 The American Phytopathological Society
With this arsenal of fungicides, apple growers follow different scab management strategies, from using only protectant fungicides applied prior to an infection period (preinfection) to using only curative fungicides applied after an infection (postinfection). Most growers, however, use a combination of these two strategies. Protectant fungicides generally are used early in the season when there are only few leaves or when infection periods can be forecasted. Curative fungicides are used when a protectant fungicide applied before the infection was washed off by rain, a protectant fungicide was not applied prior to the infection period, or the risk of primary infection was very high (large amount of ascospore ejected, several new leaves are unprotected, and severe infection period). Demethylation inhibitor fungicides (DMIs) and strobilurin-based fungicides (QoIs) are the two principal classes of fungicides used in postinfection management of apple scab in Quebec. Fungicides from these classes are prone to selecting for development of resistance in $V$. inaequalis. Sterol inhibitors specifically target C-14- demethylation of 24 methylenedihydrolanosterol, disrupting fungal sterol biosynthesis $(17,32)$. Resistance mechanisms to DMIs include overexpression of the CYP51A1 gene from $V$. inaequalis, as well as efflux mechanisms $(4,26)$ and point mutations $(5,6)$. DMI resistance in apple scab is well documented $(9,14,21-$ 25,30,33-35,38) and several cases of practical resistance have been reported, including two in northeastern North America $(2,23)$. Resistance to DMIs is quantitative $(7,11,15,16,20,36,37)$, presumably controlled by more than one gene; with the consequence that loss of sensitivity by the pathogen is gradual, following a multistep process. The sensitivity of the fungus slowly deviates from the original baseline values and may reach a point at which disease control is affected. This process may be detected easily with laboratory procedures, but the critical loss of fungicide efficacy point is more difficult to identify.

In Quebec, QoIs are not used as commonly as DMIs for apple scab management. QoIs are suggested in fungicide alternating programs as a strategy to slow down fungicide resistance development (8). This class of fungicide acts as an inhibitor of fungal mitochondrial respiration by binding to the mitochondrial cytochrome bc1 complex subunit and disrupting electron transport $(40,43)$. Even though strobilurins have been described as being more active against spore germination and host penetration (12), this class of fungicides is used mostly in postinfection application, at least in Quebec orchards. Resistance mechanisms to QoIs are complex but fairly well documented $(1,8,10,13,19,29)$. Although no cases of practical resistance have been reported for apple scab in North America, strobilurins are prone to quantitative shifts from baseline sensitivities, characterized by a slow decline in disease control due to the presence of minor resistance genes that contribute to the avoidance of the intended effects of the fungicide. QoI resistance can also be qualitative in nature, through the emergence of isolates with mutational amino acid exchanges in the cytochrome target site, mostly G143A for $V$. inaequalis $(27,44)$, that are easily detectable with molecular tools, although only after resistance has occurred. Quantitative shifts can be detected easily with laboratory tests, provided that baseline data are available for the area of interest. 
The extent of the shift from the original, preregistration sensitivities will define the loss of control that can be attributed to the resistance acquired by the fungi. Because several genes are involved in quantitative shifts, disease control is dose dependent, which is not the case for qualitative shifts.

No fungicide resistance survey has been undertaken in Quebec since 1994, when baseline sensitivities were assessed for fenarimol (3), a DMI that never received registration for use on apple in Quebec. Some cases of declining levels of control of apple scab in the past few years have led to the belief that fungicide resistance might have developed in some orchards. Because of the lack of data on fungicide resistance, the only basis of comparison are studies conducted in New York State on DMIs $(18,23,37)$ and QoIs $(27,28,39)$. Hence, the objectives of this study were to establish baseline sensitivities for Quebec, compare those baseline sensitivities with the published data from New York State, and conduct a survey in orchards throughout the province to assess the incidence of isolates of $V$. inaequalis that are insensitive to the DMI fungicide myclobutanil and to the QoI kresoxim-methyl. In addition, three potential cases of practical resistance reported by advisors or growers were studied to characterize their $V$. inaequalis populations in terms of the shift from the baseline, comparison with the provincial mean, and population composition. Because of the importance of cross-resistance in antiresistance strategies, the present study also investigated cross-resistance between myclobutanil and kresoxim-methyl and between two DMIs, myclobutanil and flusilazole, another DMI registered for apple scab control in Quebec. This data can be useful to growers to forecast eventual loss of sensitivity to other products based on already available data.

\section{MATERIALS AND METHODS}

Materials. Commercial formulations of myclobutanil (Nova 40W, Dow AgroSciences), flusilazole (Nustar 20DF, DuPont) and kresoxim-methyl (Sovran 50, BASF) were obtained from Centre Agricole Bienvenue Inc. (Rougemont, QC, Canada). Potato dextrose agar (PDA) was obtained from Difco Laboratories (Detroit). Disposable petri dishes ( 150 by 15 mm) were obtained from Fisher Scientific (Whitby, ON, Canada). All other chemicals were obtained from Sigma-Aldrich (St. Louis), unless otherwise stated.

Origin of all $V$. inaequalis isolates. The populations described in this article were collected in 2003 from 60 different orchards located in five different appleproducing regions of Quebec. A minimum of 1 and a maximum of 31 isolates from each orchard were tested. Details on the distribution of the orchards and isolates are provided in Table 1.

Monoconidial isolates. Each isolate originated from a distinct leaf and from a distinct lesion. Methods previously described were used to obtain monoconidial cultures of $V$. inaequalis $(19,37)$. In brief, leaves with distinct sporulating scab lesions were stored in brown paper bags in the freezer for a maximum of 6 months or individual lesions were cut out and placed in 2-ml Eppendorf tubes and kept at room temperature for a maximum of 3 months. Individual lesions were immersed in $1 \mathrm{ml}$ of water, and the suspension was spread onto PDA medium. After $24 \mathrm{~h}$, a single germinated conidium was transferred to PDA containing antibiotics (tetracyclin at $15 \mathrm{mg} / \mathrm{liter}$ and novobiocin at 100 $\mathrm{mg}$ /liter). After further growth, the isolate was ready for the subsequent tests.

Baseline isolates. The isolates used to establish baseline sensitivities to myclobutanil and kresoxim methyl were collected in 2003 from organic orchards or from never-treated backyard apple trees separated from any commercial orchards by at least $10 \mathrm{~km}$.

Commercial orchards. Diseased leaves were collected in five different regions of Quebec: Laurentides, Montérégie, Quebec City region, Missisquoi-Estrie, and southwestern Quebec. Sampling was done in the summer of 2003, between 2 June and 1 August. The sampled orchards were selected to include various incidences of apple scab and diverse fungicide spray schedules.

Specific orchards. Three orchards were sampled more intensively. These orchards were chosen because scab control failure had led to a suspicion of DMI resistance. Orchards 1 and 2 were located in Rougemont, Montérégie $\left(45^{\circ} 24^{\prime} \mathrm{N}, 73^{\circ} 3^{\prime}\right.$ $\mathrm{W})$, and orchard 3 was located in St.-

Table 1. Location of apple orchards surveyed in 2003 and number of isolates tested for sensitivity of Venturia inaequalis to myclobutanil and kresoxim-methyl ${ }^{\mathrm{a}}$

\begin{tabular}{lccccc}
\hline & \multicolumn{2}{c}{ Myclobutanil } & & \multicolumn{2}{c}{ Kresoxim-methyl } \\
\cline { 2 - 3 } \cline { 5 - 6 } Region & Orchards & Isolates & & Orchards & Isolates \\
\hline Laurentides & 13 & 56 & & 13 & 50 \\
Montérégie & 11 & 89 & & 11 & 97 \\
Missisquoi-Estrie & 9 & 58 & & 9 & 68 \\
Quebec City region & 6 & 10 & & 8 & 16 \\
Southwestern Quebec & 9 & 25 & & 8 & 20 \\
Total & 48 & 238 & & 49 & 251 \\
\hline
\end{tabular}

${ }^{a}$ Data indicate number of orchards surveyed and number of monoconidial isolates tested for sensitivity to the fungicide.
Joseph-du-Lac, Laurentides $\left(45^{\circ} 30^{\prime} \mathrm{N}\right.$, $\left.74^{\circ} 4^{\prime} \mathrm{W}\right)$. All three orchards had a spray schedule in which captan and mancozeb were used in protectant applications and DMIs were used in postinfection applications during the primary scab season. They all had a very high incidence of foliar and fruit scab during the 2003 season.

In vitro sensitivity tests. Sensitivities of $V$. inaequalis isolates to myclobutanil, flusilazole, and kresoxim-methyl were evaluated. Commercial formulations of fungicides were dissolved in water and incorporated into the autoclaved medium, which had been cooled to $55^{\circ} \mathrm{C}$. Mycelial plugs measuring $5 \mathrm{~mm}$ in diameter were removed with a cork borer from the margin of an actively growing colony of $V$. inaequalis and placed on PDA medium amended with increasing doses of fungicides and on unamended PDA medium. Ten different isolates were placed per petri dish (150 $\mathrm{mm}$ in diameter), and the procedure was repeated twice. The fungicide concentrations used were $0,0.05,0.1,0.5$, and $10 \mu \mathrm{g} / \mathrm{ml}$ a.i. for myclobutanil and 0 , $0.05,0.1,0.5,1$, and $10 \mu \mathrm{g} / \mathrm{ml}$ a.i. for kresoxim-methyl. After 4 weeks of incubation at $18^{\circ} \mathrm{C}$, radial growth was measured with a digital calliper (CE, model 111-411) as the average of two diameters perpendicular to each other, minus the initial plug diameter. Relative growth values were defined as (mean mycelial expansion [amended medium]/mean mycelial expansion [control] $) \times 100$. The $50 \%$ effective dose $\left(E_{50}\right)$ values were defined as the fungicide concentration, in $\mathrm{ppm}$ a.i., at which $50 \%$ of the radial growth was inhibited, as calculated by regressing mycelial expansion against the $\log 10$ of fungicide concentration. For specific isolates that were retested in QoI sensitivity tests, salicylhydroxamic acid (SHAM) was added at a concentration of $100 \mu \mathrm{g} / \mathrm{ml}$ to the growth medium.

Cross-sensitivity in $\boldsymbol{V}$. inaequalis. Cross-sensitivity was investigated by comparing the $\mathrm{ED}_{50}$ values for 202 isolates tested for both myclobutanil and kresoximmethyl. In addition, among all the isolates tested for myclobutanil, 93 were arbitrarily chosen to be tested for their sensitivity to another DMI, flusilazole. Sensitivity to flusilazole was tested using the methodology described for testing sensitivity to myclobutanil.

Data analysis. The means of the $\mathrm{ED}_{50}$ values from different populations were compared based on the Kolmogorov Smirnov test, and the frequency distribution of log-transformed $\mathrm{ED}_{50}$ values for each population was analyzed using univariate procedures. Classes of $\mathrm{ED}_{50}$ values were determined by measuring the range factor (highest $\mathrm{ED}_{50}$ to lowest $\mathrm{ED}_{50}$ ) from repeated in vitro tests with a subsample of 20 isolates (39). The correlation between the $\mathrm{ED}_{50}$ values for myclobutanil and kresoxim-methyl $(n=202)$ and between 
the $\mathrm{ED}_{50}$ values for myclobutanil and flusilazole $(n=93)$ was analyzed based on the Spearman correlation coefficient. All analyses were performed using the SYSTAT 11 software program (Systat Software, Richmond, CA).

\section{RESULTS}

Baseline sensitivity of $\boldsymbol{V}$. inaequalis to myclobutanil. A baseline population $(n=$ 34) constructed with isolates from backyard apple trees and untreated abandoned trees yielded a mean $\mathrm{ED}_{50}$ of $0.064 \mu \mathrm{g} / \mathrm{ml}$, very close to what has been reported previously $(2,18,23)$, with values ranging from 0.010 to $0.240 \mu \mathrm{g} / \mathrm{ml}$ (Fig. 1). This represents a range factor (highest $\mathrm{ED}_{50}$ to lowest $\mathrm{ED}_{50}$ ) of 24 and a resistance factor (highest $\mathrm{ED}_{50} /$ mean $\mathrm{ED}_{50}$ ) of 3.75. This extent of values is far less than what has been described previously for myclobutanil (18). All baseline isolates are within boundaries established by Köller et al. (23) for sensitive isolates. The frequency distribution of $\mathrm{ED}_{50}$ values was lognormal $(P=$ 0.05).

Sensitivity of $V$. inaequalis to myclobutanil in commercial orchards. Forty-eight commercial orchards from five different regions in the province of Quebec (Canada) were sampled for scab lesions to construct a population representative of the whole apple-producing area. In all, 1 to 30 isolates per orchard were tested for a total of 238 isolates and yielded a mean $\mathrm{ED}_{50}$ of $2.600 \mu \mathrm{g} / \mathrm{ml}$, with values ranging from 0.017 to 10.375 (Fig. 2), giving a range factor of 610 and a resistance factor of 4 (Table 2). Only $16.8 \%$ of the commercial isolates were within the baseline values and $71.4 \%$ were above the threshold set by Köller et al. (23) for resistance to myclobutanil. This proportion is much higher than the proportion of resistant isolates found in two orchards that were diagnosed as DMIresistant in Nova Scotia (2) and Michigan (23) and similar to those found for an experimental orchard in New York state (19; Table 2). The mean $\mathrm{ED}_{50}$ values for the population of $V$. inaequalis from commercial orchards $(2.600 \mu \mathrm{g} / \mathrm{ml})$ was significantly $(P<0.05)$ higher than the mean $\mathrm{ED}_{50}$ values of the baseline population $(0.064 \mu \mathrm{g} / \mathrm{ml})$ according to the Kolmogorov-Smirnov test.

Sensitivity of $V$. inaequalis to myclobutanil in three specific orchards. Orchards 1 and 2, located in Rougemont, and orchard 3, in St.-Joseph-du-Lac, were more intensively investigated. In these orchards, fungicide resistance to myclobutanil was suspected because of declining scab control when DMI fungicides were used. In orchards 1, 2, and 3, 23, 29, and 20 isolates, respectively, yielded mean $\mathrm{ED}_{50}$ values of $1.618,3.079$, and 1.500 $\mu \mathrm{g} / \mathrm{ml}$. Orchards 1 and 3 are under the provincial mean and orchard 2 is above. Resistant isolates, according to criteria set by Köller et al. (23), accounted for 39, 76, and $85 \%$ of the isolates tested. According to the Kolmogorov-Smirnov test, the mean $\mathrm{ED}_{50}$ values for the population of $V$. inaequalis from orchards 1,2 , and 3 were significantly $(P<0.05)$ higher than the mean $\mathrm{ED}_{50}$ values of the baseline population $(0.064 \mu \mathrm{g} / \mathrm{ml}) . \mathrm{ED}_{50}$ for orchard 2 was not significantly different whereas $\mathrm{ED}_{50}$

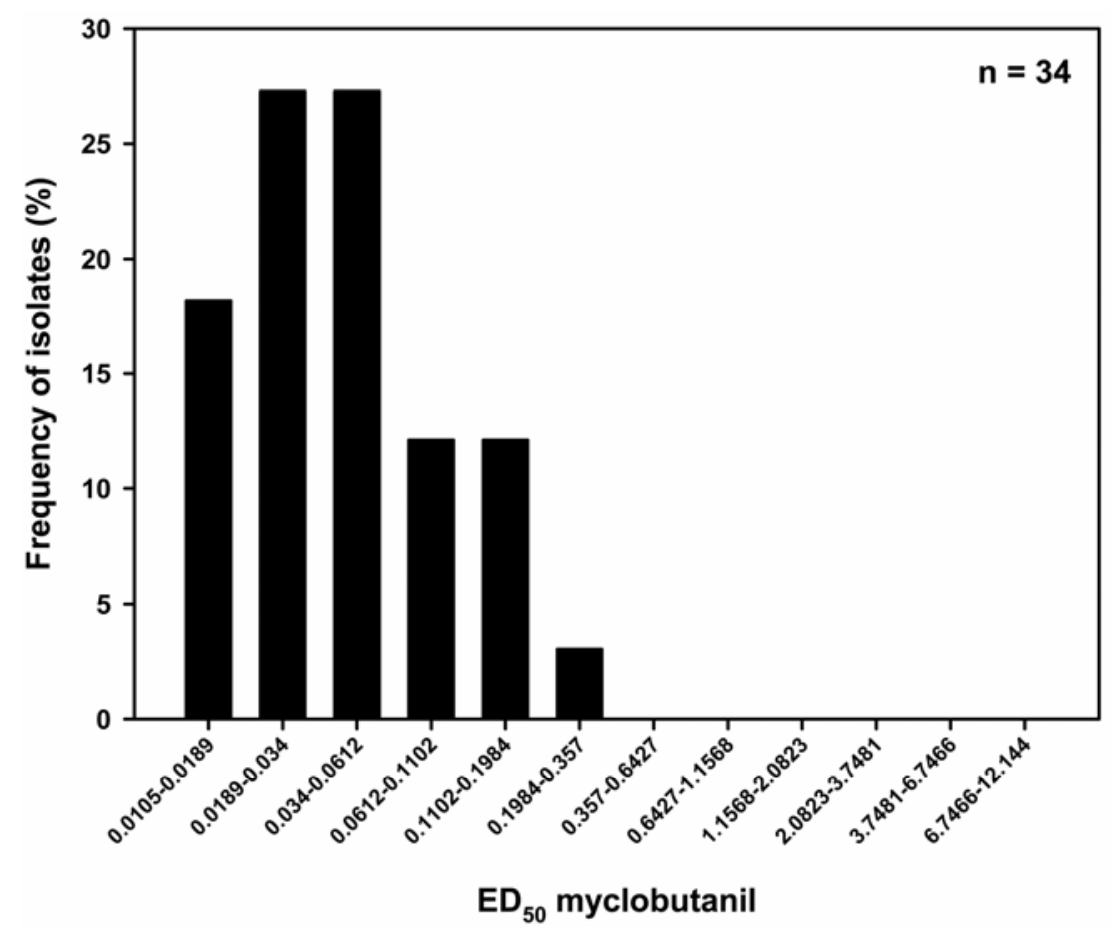

Fig. 1. Frequency distributions of Venturia inaequalis isolate baseline sensitivities to myclobutanil based on 34 isolates from backyard and abandoned untreated trees sampled in Quebec during the summer of 2003. The $50 \%$ effective dose (fungicide concentration at which $50 \%$ of the radial growth was inhibited; $\left.\mathrm{ED}_{50}\right)$ values $(\mu \mathrm{g} / \mathrm{ml})$ are based on mycelial radial growth on potato dextrose agar amended with different doses of the fungicides for 4 weeks.

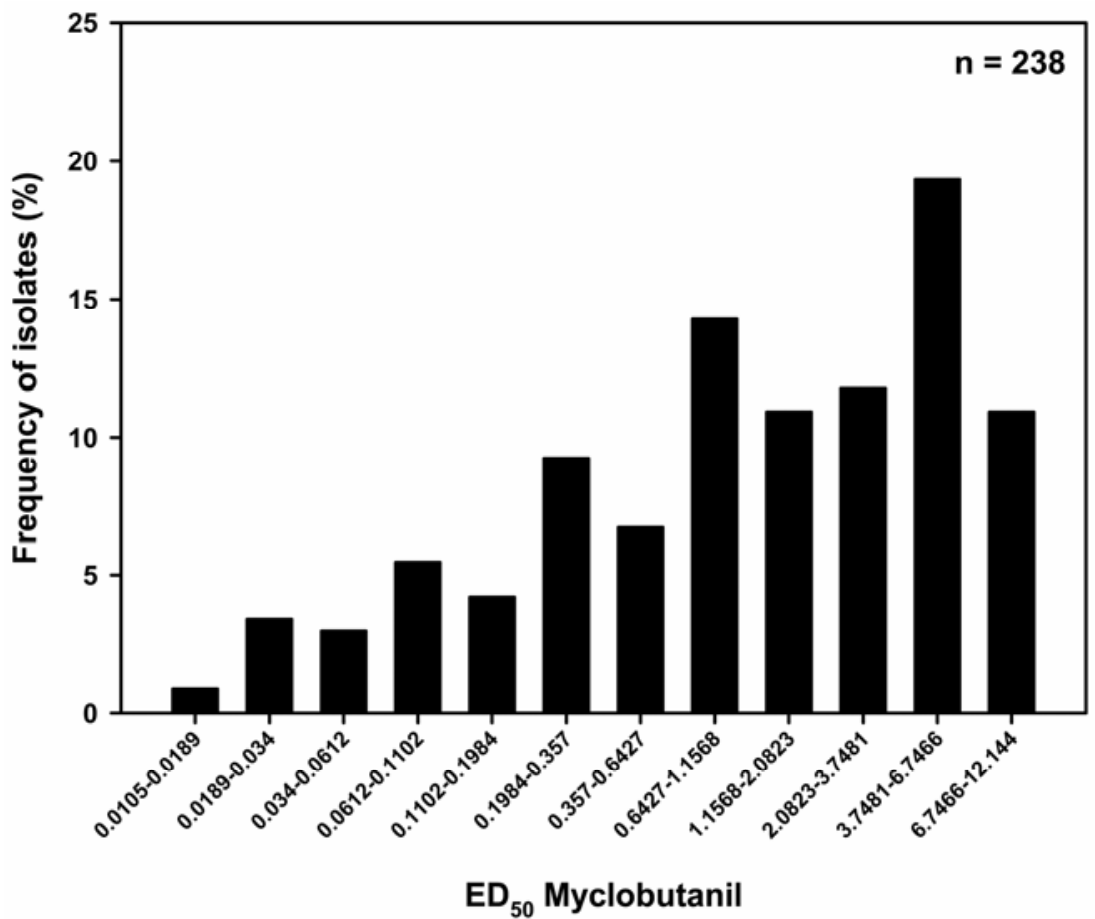

Fig. 2. Frequency distribution of $50 \%$ effective dose (fungicide concentration at which $50 \%$ of the radial growth was inhibited; $\mathrm{ED}_{50}$ ) values for myclobutanil of Venturia inaequalis isolate sensitivities based on 238 isolates from commercial orchards sampled in Quebec during the summer of 2003. ED 50 values $(\mu \mathrm{g} / \mathrm{ml})$ are based on mycelial radial growth on potato dextrose agar amended with different doses of the fungicides for 4 weeks. 
for orchards 1 and 3 were significantly different $(P<0.01)$ from the mean $\mathrm{ED}_{50}$ values for the population of $V$. inaequalis from commercial orchard $(2.600 \mu \mathrm{g} / \mathrm{ml})$. The characteristics of these orchards regarding myclobutanil resistance are compared with those reported in the literature for baseline populations and populations with practical resistance in Table 2 .

Baseline sensitivity of $\mathrm{V}$. inaequalis to kresoxim-methyl. A baseline population $(n=29)$ constructed with isolates from backyard apple trees and untreated abandoned trees yielded a mean $\mathrm{ED}_{50}$ of 0.092 $\mu \mathrm{g} / \mathrm{ml}$ (Fig. 3), much lower than the value obtained by Olaya et al. (29) but similar to a trifloxystrobin-sensitive isolate in another study (39). Individual $\mathrm{ED}_{50}$ values varied from 0.003 to $0.711 \mu \mathrm{g} / \mathrm{ml}$, giving a range factor of 237 and a resistance factor of 7.7. The frequency distribution of $\mathrm{ED}_{50}$ values was lognormal $(P=0.05)$.

Sensitivity of $V$. inaequalis to kresoxim-methyl in commercial orchards. The distribution of a total of 251 isolates tested in vitro for their sensitivity to kresoxim-methyl is presented in Figure 4. The frequency distribution of $\mathrm{ED}_{50}$ values was lognormal $(P=0.05)$. The mean $\mathrm{ED}_{50}$ value of $6.096 \mu \mathrm{g} / \mathrm{ml}$ was strongly influenced by the incidence of highly insensitive isolates which did not show dose response to the kresoxim-methyl. The mean $\mathrm{ED}_{50}$ fell to 3.005, 2.314, 1.466, and $0.741 \mu \mathrm{g} / \mathrm{ml}$ when the $8,11,19$, and 32 most insensitive isolates were excluded from the calculation. Thirty of the most resistant isolates, which displayed little or no dose response $\left(\mathrm{ED}_{50}\right.$ higher than the maximum in vitro fungicide dose) were retested for their sensitivity to kresoximmethyl with the addition of SHAM, an inhibitor of alternative oxidase (AOX) (27), at $100 \mu \mathrm{g} / \mathrm{ml}$ in the growth medium. AOX is responsible for a resistance mechanism involving alternative respiration which is thought to be active in the mycelial growth phase in vitro but of no adverse effect on disease control in planta $(29,45)$. Strong $(>98 \%)$ inhibition was observed for all isolates in the presence of SHAM and kresoxim-methyl at $10 \mu \mathrm{g} / \mathrm{ml}$ (data not shown). These results suggest that in vitro resistance may be explained by highly active alternative respiration mechanisms. However, one case of high incidence of insensitive isolates was observed at the Frelighsburg Experimental Farm (Fig. 5). Of the 38 isolates tested for this orchard, $24(63 \%)$ fell out of baseline sensitivities, including 6 which had no dose response to kresoxim-methyl and 8 which were very poorly inhibited, never reaching $50 \%$ of mycelial growth inhibition at the higher dose of $10 \mu \mathrm{g} / \mathrm{ml}$. Prior to sampling in 2003, the experimental plot had been sprayed only once with kresoxim-methyl, in 2000. To our knowledge, this would represent the first reported case of a population of $V$. inaequalis naturally resistant to QoIs.

Cross-sensitivity in $V$. inaequalis. In all, 202 isolates representing the range of sensitivity to DMI and QoI fungicides were tested for their sensitivity to both myclobutanil and kresoxim-methyl (Fig. $6)$. The Pearson correlation coefficient was low $(r=0.089, P>0.05)$, indicating that there was no significant correlation between sensitivity to myclobutanil and sensitivity to kresoxim-methyl. However, based on the Pearson correlation coefficient, there was a significant correlation between the 93 isolates tested for myclobutanil and flusilazole $(r=0.318, P<$ 0.002).

\section{DISCUSSION}

DMI fungicides frequently are used for apple scab management in the province of Quebec. Despite the routine use of DMIs, mainly myclobutanil, to inhibit mycelial development in the recommended postinfection period, no dramatic disease control failures have been directly attributed to

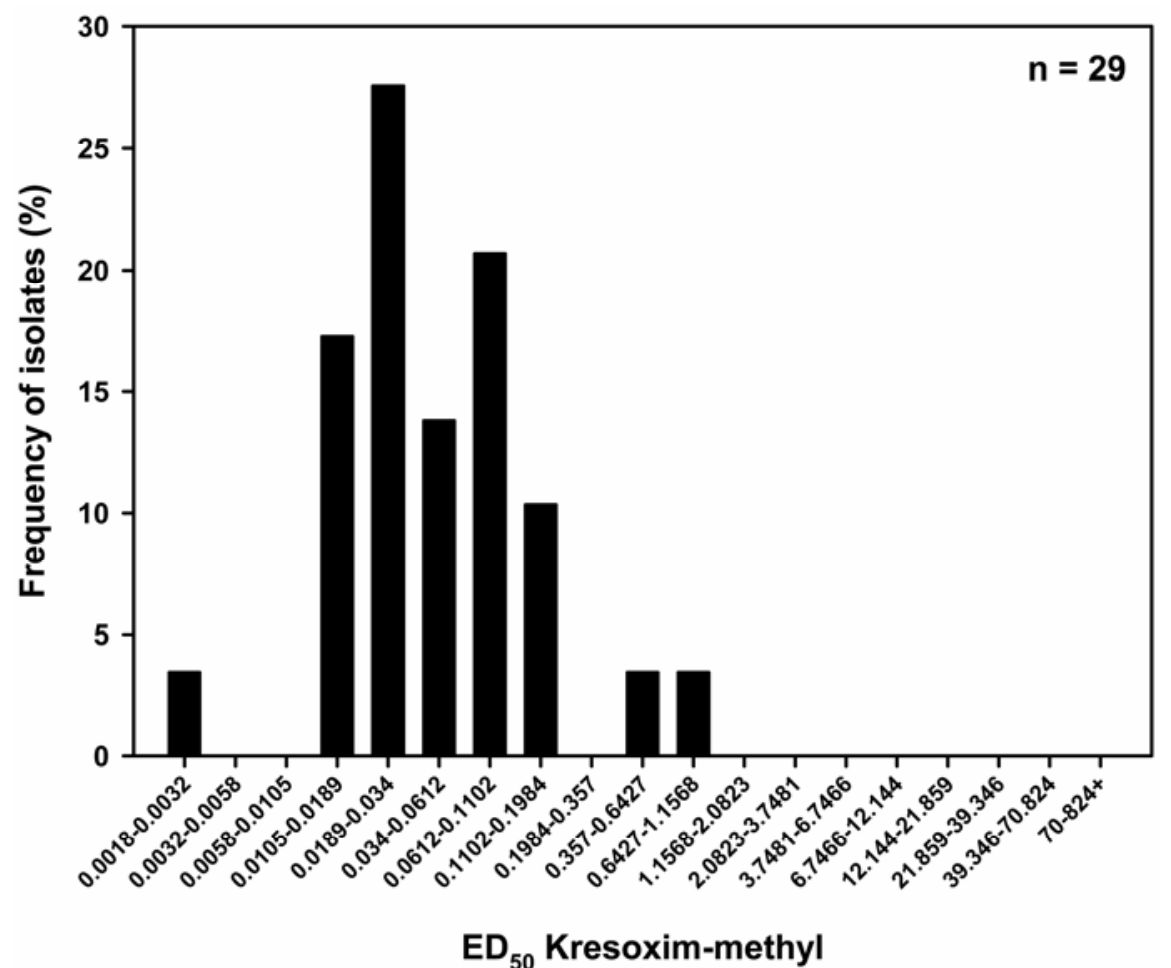

Fig. 3. Frequency distribution of Venturia inaequalis isolate baseline sensitivities to kresoxim-methyl based on 29 isolates from backyard and abandoned untreated trees sampled in Quebec during the summer of 2003. The $50 \%$ effective dose (fungicide concentration at which $50 \%$ of the radial growth was inhibited; $\left.\mathrm{ED}_{50}\right)$ values $(\mu \mathrm{g} / \mathrm{ml})$ are based on mycelial radial growth on potato dextrose agar amended with different doses of the fungicides for 4 weeks without addition of salicylhydroxamic acid.

Table 2. Comparison of demethylation inhibitor fungicide resistance characteristics for orchards from this study and published reports

\begin{tabular}{|c|c|c|c|c|c|c|}
\hline Orchard $^{\text {a }}$ & $\begin{array}{c}\text { Number of } \\
\text { isolates }\end{array}$ & $\begin{array}{c}\text { Sensitive isolates } \\
(\%)\end{array}$ & $\begin{array}{c}\text { Resistant isolates } \\
(\%)\end{array}$ & $\begin{array}{l}\text { Mean } \\
\text { ED }_{50}{ }^{a}\end{array}$ & $\begin{array}{c}\text { Median } \\
\text { ED }_{50}{ }^{a}\end{array}$ & $\begin{array}{c}\text { Highly resistant } \\
(7.8)\end{array}$ \\
\hline Baseline New York ${ }^{b}$ & 627 & 97.8 & 2.2 & 0.058 & $\ldots$ & 0 \\
\hline Baseline Quebec & 34 & 100 & 0 & 0.064 & 0.038 & 0 \\
\hline Resistance threshold ${ }^{b}$ & 104 & 56.7 & 43.3 & $\ldots$ & $\ldots$ & $\ldots$ \\
\hline XP orchard $^{\mathrm{b}}$ & 67 & 34.3 & 65.7 & $\ldots$ & $\ldots$ & $\ldots$ \\
\hline Province of Quebec & 238 & 29.6 & 71.4 & 2.6 & 1.295 & 4.2 \\
\hline Orchard 1 & 23 & 60.9 & 39.1 & 1.618 & 0.224 & 13 \\
\hline Orchard 2 & 29 & 24.1 & 75.9 & 3.079 & 3.051 & 0 \\
\hline Orchard 3 & 20 & 15 & 85 & 1.5 & 1.091 & 0 \\
\hline
\end{tabular}

\footnotetext{
${ }^{\mathrm{a}} \mathrm{ED}_{50}=50 \%$ effective dose; the fungicide concentration at which $50 \%$ of the radial growth was inhibited.
}

b From Köller et al. (19). 
fungicide resistance. This phenomenon can be explained, at least in part, by the pattern of DMI usage, which includes the use of DMI alone but also mixed with a protectant fungicide such as mancozeb or captan. In the latter case, the protectant fungicide may be providing the majority of the disease control and, therefore, may be masking the loss of control that would otherwise occur with DMI fungicides. Consequently, the use of DMIs, a family of fungicides prone to resistance, continues to be widespread in Quebec. This study was initiated, in part, to address growers' concerns regarding the incidence of DMIinsensitive isolates of $V$. inaequalis in apple-production areas of Quebec. Sensitivity of kresoxim-methyl also was studied because this fungicide is often recommended as an alternative to DMI fungicide. In this study, the sensitivity of populations of $V$. inaqualis never exposed and exposed to both myclobutanil and kresoxim-methyl were established. Sensitivity was established from in vitro tests but care must be taken in interpreting the results in terms of field resistance (31).

One of the objectives of this study was to compare baseline data for the province of Quebec with baseline data reported for New York State and to compare the sensitivity of populations of $V$. inaequalis from commercial orchards in the province of Quebec and commercial orchards in the northeastern United States. Providing that baseline sensitivities were similar, the situation in the province of Quebec can be compared with previously published data on baseline shift, and laboratory and practical resistance. For myclobutanil, baseline sensitivities were almost identical with mean $\mathrm{ED}_{50}$ values of 0.064 and 0.056 $\mu \mathrm{g} / \mathrm{ml}$ for the province of Quebec and New York State, respectively (23). However, the range of $\mathrm{ED}_{50}$ values obtained in this study was narrower, with a range factor (highest $\mathrm{ED}_{50}$ to lowest $\mathrm{ED}_{50}$ ) of 24, about 4 times smaller than the values reported by Köller et al. (23) and 12 times smaller than values from Smith et al. (37) for flusilazole. Based on this, the magnitude of the shifts assuming that the starting point was equivalent was compared. Accordingly, Köller et al. (23) set the resistance threshold for myclobutanil at $0.46 \mu \mathrm{g} / \mathrm{ml}$, and this also will serve us in the interpretation of the data. Baseline sensitivities established in this study for the province of Quebec are similar to those obtained by Braun et al. (2), in Nova Scotia.

As illustrated in Table 2, more than $70 \%$ of the commercial isolates displayed $\mathrm{ED}_{50}$ values higher than the New York State threshold. This is much higher than the proportion of resistant isolates found in two orchards that were diagnosed as DMI resistant in Nova Scotia and Michigan and similar to those found for an experimental orchard in New York State (19). Based on these criteria, the province of Quebec, as a

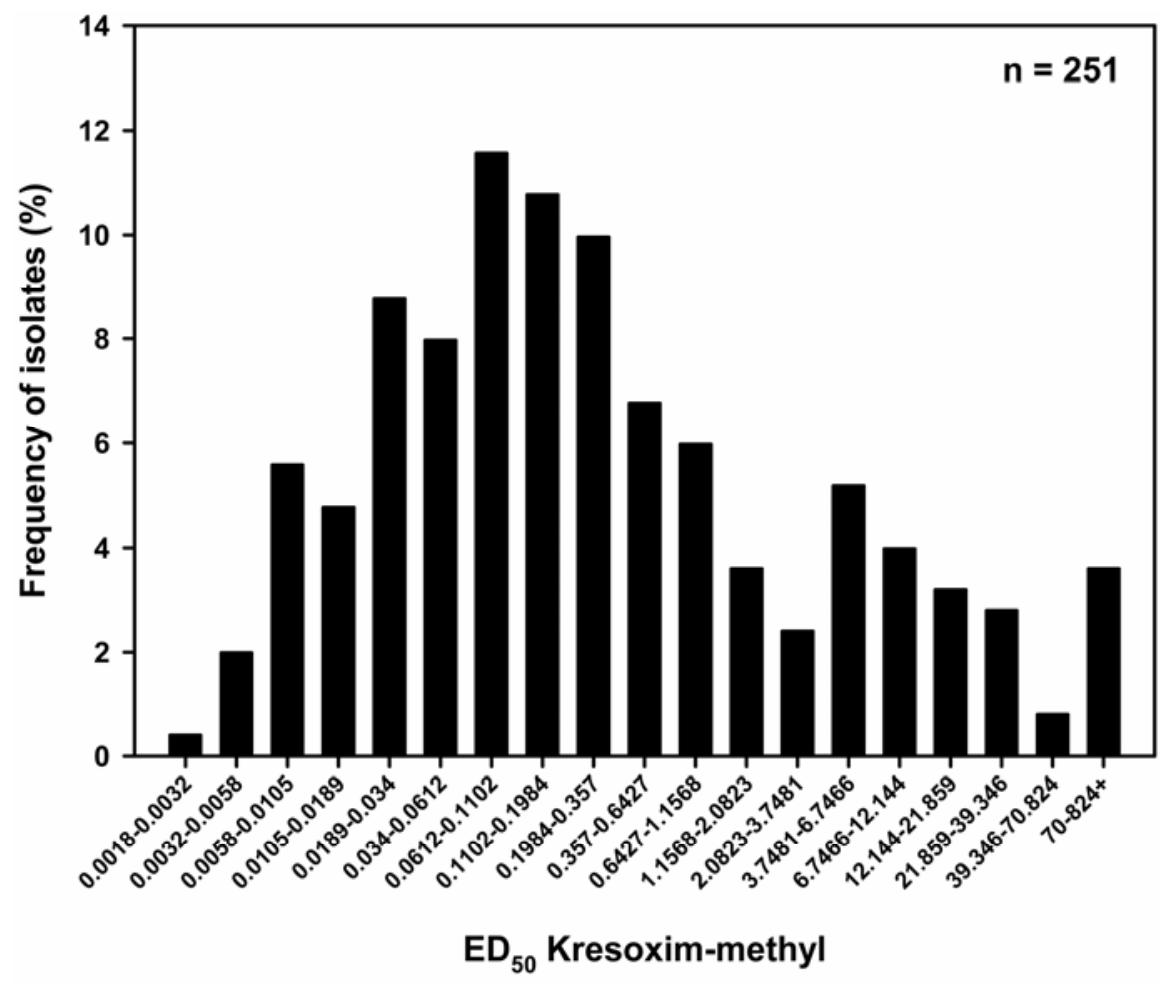

Fig. 4. Frequency distribution of $50 \%$ effective dose (fungicide concentration at which $50 \%$ of the radial growth was inhibited; $\mathrm{ED}_{50}$ ) values for kresoxim-methyl of Venturia inaequalis isolate sensitivities based on 251 isolates from commercial orchards sampled in Quebec during the summer of 2003. $\mathrm{ED}_{50}$ values $(\mu \mathrm{g} / \mathrm{ml})$ are based on mycelial radial growth on potato dextrose agar amended with different doses of the fungicides for 4 weeks without addition of salicylhydroxamic acid.

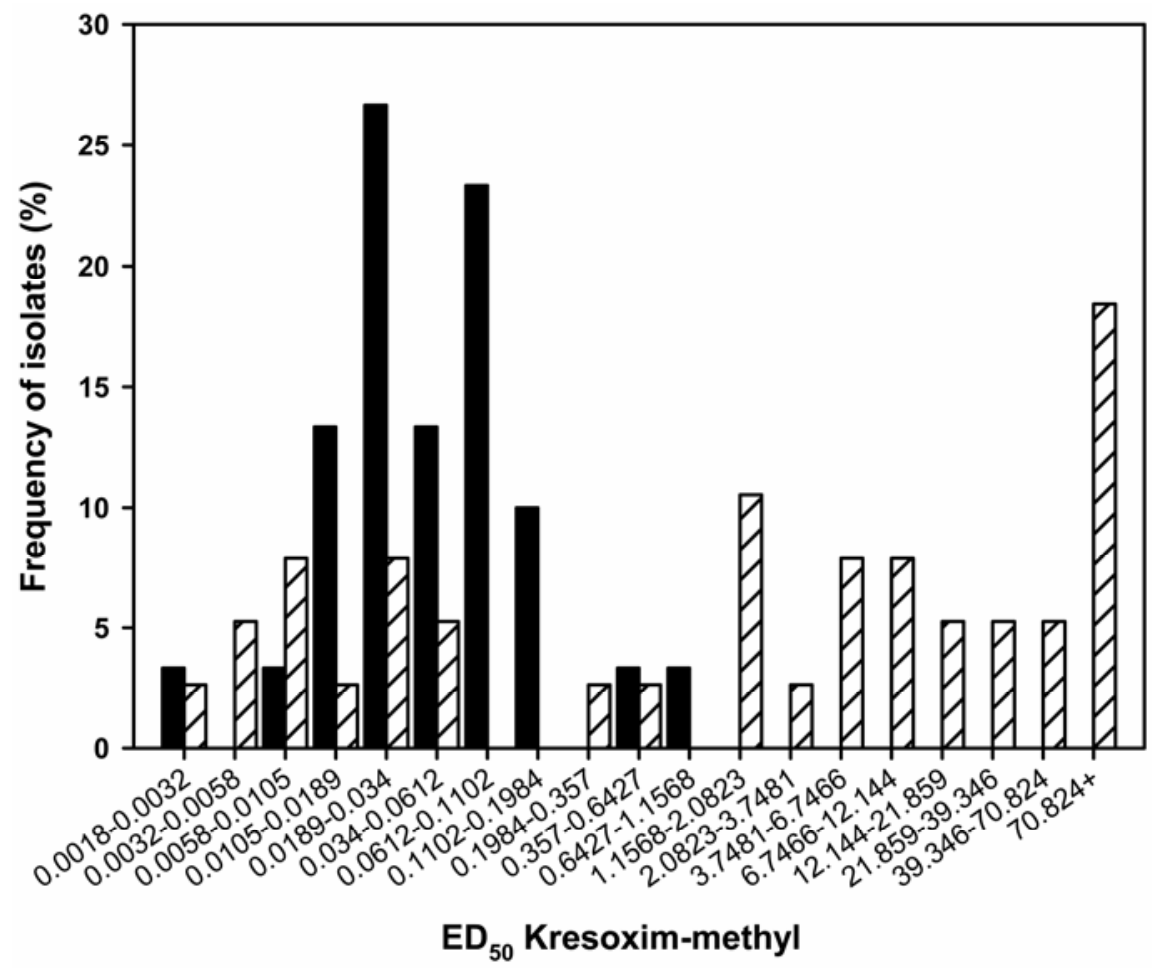

Fig. 5. Frequency distributions of sensitivities of two Venturia inaequalis populations to kresoxim-methyl. Dark bars represent previously shown baseline sensitivities, and dashed bars represent sensitivity distribution from a population $(n=38)$ sampled from the Frelighsburg Experimental Farm. The 50\% effective dose (fungicide concentration at which 50\% of the radial growth was inhibited; $\left.\mathrm{ED}_{50}\right)$ values $(\mu \mathrm{g} / \mathrm{ml})$ are based on mycelial radial growth on potato dextrose agar amended with different doses of the fungicides for 4 weeks without addition of salicylhydroxamic acid. 
whole, should be considered as fully DMI resistant because the combined mean $\mathrm{ED}_{50}$ value for all orchards is more than 5.5 times higher than the threshold set for myclobutanil resistance. However, apple scab control is still at an acceptable level in the vast majority of orchards even if disease control relies heavily on the use of postinfection DMI. The results of this study are surprising because such strong shifts from baseline sensitivity have not been reported. Based on the results on this study, one may conclude that $V$. inaequalis populations from most orchards of the province of Quebec are resistant to myclobutanil and that control failure is expected. Even if control failure has not been widely reported, the results suggest that the situation may be at a critical point, practical resistance being the next step if no anti-resistance measures are implemented rapidly. The question remains: how could such high frequencies of insensitive isolates spread widely across the province without causing serious disease control problems?

As reported in Table 2, various populations have been characterized for the occurrence of highly resistant isolates, their mean and median $\mathrm{ED}_{50}$ value, and proportion of sensitive isolates. Orchard 1 was selected because of extremely high scab incidence ( $>25 \%$ scabbed leaves in early summer 2003). In this orchard, susceptible cultivars such as McIntosh and Cortland were not harvested because of poor fruit quality due to scab. Defoliation due to apple scab was common in midsummer. Orchard 2 was selected because of fungicide resistance concerns; DMIs were used

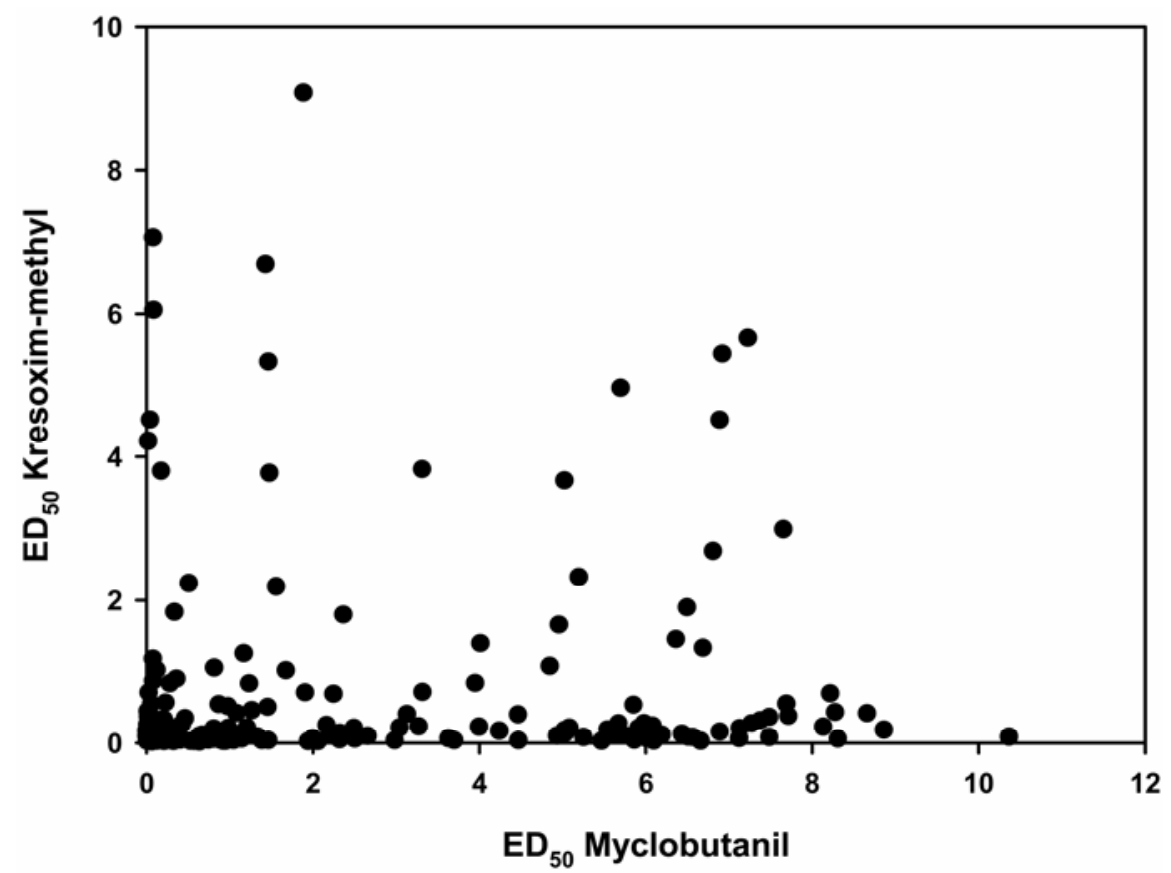

Fig. 6. Fifty percent effective dose (fungicide concentration at which $50 \%$ of the radial growth was inhibited; $\left.\mathrm{ED}_{50}\right)$ values $(\mu \mathrm{g} / \mathrm{ml})$ for kresoxim-methyl and myclobutanil for 202 isolates of Venturia inaequalis sampled throughout Quebec in the summer of 2003. appropriately in postinfection for all major primary infections but scab incidence was at a commercially unsatisfactory level $(>10 \%)$ in 2003. Orchard 3 was selected because scab control failure expressed as outburst of foliar scab in specific parts of the orchard was reported after applications of myclobutanil in 2003. Even though orchards 1 and 3 had disease control issues, their respective sites were under the provincial mean $\mathrm{ED}_{50}$, which is puzzling. Of all three orchards, highly resistant isolates were found only in orchard 1. Moreover, this orchard is in line with a resistance threshold previously established (23). It would have been interesting to accumulate data on disease control with an appropriate fungicide spray schedule. Unfortunately, even though subsequent disease assessments were made, management was negligent in 2004 and 2005 and no other data were recorded. Thus, it is possible that disease control failure was imputable to inadequate fungicide application. The population of $V$. inaequalis in orchard 2 probably was near practical resistance. Even though mean $\mathrm{ED}_{50}$ was only 1.2 times higher than the provincial mean, the proportion of insensitive isolates was above the values obtained for the New York experimental farm, qualified as fully DMI resistant (19). Scab incidence was above commercially acceptable levels but remained under control throughout. In 2004 and 2005, the grower used a more conservative, protection-based schedule, with anilinopyrimidine- and strobilurinbased fungicides used when postinfection sprays were needed. Scab incidence was reduced to a low level ( 1 to $2 \%$ scabbed leaves) and no fungicide resistance monitoring was done. Orchard 3 might be a typical example of what could happen to Quebec orchards if no strict anti-resistance strategies are implemented and if DMI use is still routine.

Most studies done on $V$. inaequalis sensitivity to mitochondrial respiration inhibitors were done on the conidia germination stage because strobilurins are more effective against this phase of development of the fungus and, accordingly, are more commonly used in protective applications. However, because kresoxim-methyl is largely used as a postinfection fungicide in Quebec orchards, sensitivity on the mycelial development stage was assessed. Olaya et al. (29) already reported higher dose requirements to inhibit $50 \%$ of mycelial growth compared with doses required to inhibit conidia germination by $50 \%$. These authors reported that, for two isolates tested, $\mathrm{ED}_{50}$ values were 0.005 and 0.3 $\mu \mathrm{g} / \mathrm{ml}$ for conidia germination and $1 \mu \mathrm{g} / \mathrm{ml}$ for mycelium development. Olaya et al. (29) reported baseline values ranging from 0.003 to $0.140 \mu \mathrm{g} / \mathrm{ml}$ for conidia germination, with a mean $\mathrm{ED}_{50}$ of $0.02 \mu \mathrm{g} / \mathrm{ml}$. Steinfeld et al. (39) tested several strobilurins against both stages of the fungus, and reported $\mathrm{ED}_{50}$ values of $0.08 \mu \mathrm{g} / \mathrm{ml}$ for trifloxystrobin and azoxystrobin.

Our baseline study of sensitivity of mycelial development to kresoxim-methyl yielded a mean of $0.092 \mu \mathrm{g} / \mathrm{ml}$, very close to sensitive isolates described by various authors $(27,39)$ for both stages, but considerably lower than the values obtained by Olaya et al. (29); however, this may be due to the very limited number of isolates tested. It could be assumed that the baseline population in the province of Quebec is representative of a population sensitive to kresoxim-methyl and, hence, use it to detect shifts in sensitivity of $V$. inaequalis. $\mathrm{ED}_{50}$ values were broadly distributed, with a range factor of 237, slightly higher than what was reported for two other populations (29).

Commercial isolates tested $(n=251)$ yielded a bimodal population with a mean $\mathrm{ED}_{50}$ of $6.096 \mu \mathrm{g} / \mathrm{ml}$, strongly biased by the occurrence of isolates with very poor dose response. When isolates that had less than $50 \%$ inhibition at the maximum dose were not considered, mean sensitivity decreased to $0.741 \mu \mathrm{g} / \mathrm{ml}$, a value close to the upper limits of the baseline data. Hence, it may indicate the presence of a slight shift toward insensitivity even though 178 (71\%) of the commercial isolates are still within baseline range. Moreover, the mean $\mathrm{ED}_{50}$, without the highly insensitive isolates, is still under what has been reported previously for mycelial growth sensitivity (29).

As far as we know, strobilurins have not been associated with any reduction in disease control in orchards in the province of Quebec. The level of sensitivity is cur- 
rently near baseline. However, 32 isolates did not respond to high doses of kresoximmethyl. Of the 32 isolates, 30 were tested in the presence of SHAM, a potent inhibitor of AOX, thought to be responsible for cases of in vitro resistance in many organisms $(1,29,45)$. Growth of the fungus at a high dose of strobilurin with SHAM at 100 $\mu \mathrm{g} / \mathrm{ml}$ might indicate the presence of a mutant isolate and raise the possibility of qualitative resistance. It was not the case in this study because no isolates displayed significant growth in the presence of the combined respiration inhibitors. However, one interesting case is worth reporting. At the Frelighsburg Experimental Farm, 14 of the 32 isolates did not respond to a high kresoxim-methyl dose, whereas no other orchards sampled had more than 4. Furthermore, five other isolates displayed $\mathrm{ED}_{50}$ of more than $3.5 \mu \mathrm{g} / \mathrm{ml}$ (Fig. 5). Before sampling in June 2003, the plot had received only one application of QoIs, in 2001. This may be the first reported case of a population naturally insensitive to strobilurins. Alternative respiration is surely one of the causes of the insensitivity, as demonstrated by the effect of SHAM, but other mechanisms, such as detoxification of the product by the pathogen, also may be involved (42). Further studies are needed to characterize this population. Based on data from this study, the same population also seems to be resistant to DMIs and disease control is a problem year after year, with over $50 \%$ foliar and fruit scab (data not shown). Despite that, because of the overall results, strobilurins still could be considered as a good alternative to DMIs and other postinfection products in anti-resistance strategies. This was further supported by the analysis of cross-sensitivity, which showed no significant correlation between sensitivity to myclobutanil and sensitivity to kresoximmethyl. The results of the comparative $V$. inaequalis sensitivity to myclobutanil and kresoxim-methyl and to myclobutanil and flusilazole illustrated the lack of crossresistance between fungicides from different families, but also stressed the crossresistance within DMI fungicides and family in the population studied. The lack of cross-resistance between DMI and strobilurin-based fungicides observed in this study is not in accordance with other reports on V. inaequalis $(21,22)$ and Erysiphe necator (41).

This study was initiated to address advisors' and growers' concerns regarding the incidence of myclobutanil- and kresoximmethyl-insensitive isolates in Quebec's orchards. The results showed a high frequency of myclobutanil-insensitive isolates and a low frequency of kresoxim-methylinsensitive isolates. However, sensitivity was established from in vitro tests and the link between in vitro sensitivity and apple scab management is not consistent, as shown by the results of the three orchards investigated. Nevertheless, these results suggest that the use of myclobutanil and DMIs should be discontinued or reduced before practical resistance is reached. However, such recommendation may lead to increased use of kresoxim-methyl and, eventually, to resistance to QoIs, a situation that could accelerate the resistance process; or to increased usage of protectant fungicides with a higher environmental impact. Implementation of fungicide antiresistance strategies is needed; however, fungicide resistance is not the sole source of apple scab control failure. Several factors may influence fungicide efficacy, among which are fungicide mixture preparation, application rate, spraying conditions, leaf coverage, and timing of application. The best approach is probably to favor the implementation of integrated tools to apple scab management, such as sanitation-improved fungicide timing, while efficiently monitoring fungicide resistance and avoiding the loss of crucial products for growers.

\section{ACKNOWLEDGMENTS}

This work was financially supported by a Matching Investment Initiative between Agriculture and Agri-Food Canada and the Fédération des producteurs de pommes du Quebec. We thank J. Roy and G. Legault for their technical assistance.

\section{LITERATURE CITED}

1. Avila-Adame, C., Olaya, G., and Köller, W. 2003. Characterization of Colletotrichum graminicola isolates resistant to strobilurinrelated QoI fungicides. Plant Dis. 87:14261432.

2. Braun, P. G., and McRae, K. B. 1992. Composition of a population of Venturia inaequalis resistant to myclobutanil. Can. J. Plant Pathol. 14:215-220.

3. Carisse, O., and Pelletier, J. R. 1994. Sensitivity distribution of Venturia inaequalis to fenarimol in Quebec apple orchards. Phytoprotection 75:35-43.

4. Del Sorbo, G., Andrade, A. C., van Nistelrooy, J. G. M., van Kan, J. A. L., Balzi, E., and de Waard, M. A. 1997. Multidrug resistance in Aspergillus nidulans involves novel ATPbinding cassette transporters. Mol. Gen. Genet. 254:417-426.

5. Delye, C., Bousset, L., and Corio-Costet, M. F. 1998. PCR cloning and detection of point mutations in the eburicol 14 $\alpha$-demethylase (CYP51) gene from Erysiphe graminis f. sp. hordei, a "recalcitrant" fungus. Curr. Genet. 34:399-403.

6. Delye, C., Laigret, F., and Corio-Costet, M. F. 1997. A mutation in the 14 alpha-demethylase gene of Uncinula necator that correlates with resistance to a sterol biosynthesis inhibitor. Appl. Environ. Microbiol. 63:2966-2970.

7. de Waard, M. A. 1993. Recent developments in fungicides. In: Modern Crop Protection: Developments and Perspectives. J. C. Zadoks ed. Wageningen Pers., Wageningen, The Netherlands.

8. de Waard, M. A., Andrade, A. C., Hayashi, K., Schoonbeek, H., Stergiopoulos, I., and Zwiers, L. 2006. Impact of fungal drug transporters on fungicide sensitivity, multidrug resistance and virulence. Pest Manage. Sci. 62:195-207.

9. Fiaccadori, R. 1987. Sensitivity to inhibitors of sterol biosynthesis in isolates of Venturia inaequalis from Italian and Dutch orchards. Neth. J. Plant Pathol. 93:285-287.

10. Fisher, N., and Meunier, B. 2005. Re- examination of inhibitor resistance conferred by Qo-site mutations in cytochrome $b$ using yeast as a model system. Pest Manage. Sci. 61:973-978.

11. Georgopoulos, S. G., and Skylakakis, G. 1986. Genetic variability in the fungi and the problem of fungicide resistance. Crop Prot. 5:299305.

12. Gold, R. E., Ammermann, E., Köhle, H., Leinhos, G. M. E., Lorenz, G., Speakman, J. B., Stark-Urnau, M., and Sauter, H. 1996. The synthetic strobilurin BAS $490 \mathrm{~F}$ : profile of modern fungicide. In: Modern Fungicides and Antifungal Compounds. H. Lyr, H. W. Dehne, and P. E. Russell, eds. Intercept Ltd., Andover, Hampshire, UK.

13. Grasso, V., Palermo, S., Sierotzki, H., Garibaldi, A., and Gisi, U. 2006. Cytochrome $b$ gene structure and consequences for resistance to Qo inhibitor fungicides in plant pathogen. Pest Manage. Sci. 62:465-472.

14. Hildebrand, P. D., Lockhart, C. L., Newbery, R. J., and Ross, R. G. 1988. Resistance of Venturia inaequalis to bitertanol and other demethylation-inhibiting fungicides. Can. J. Plant Pathol. 10:311-316.

15. Kalamarakis, A. E., de Waard, M. A., Ziogas, B. N., and Georgopoulos, S. G. 1991. Resistance to fenarimol in Nectria haematococca var. cucurbitae. Pestic. Biochem. Physiol. 40:212-220.

16. Karaoglanidis, G. S., Karadimos, D. A., and Ioannidis, P. M. 2003. Detection of resistance to sterol demethylation-inhibiting (DMI) fungicides in Cercospora beticola and efficacy of control of resistant and sensitive strains with flutriafol. Phytoparasitica 31:373-380.

17. Köller, W. 1988. Sterol demethylation inhibitors: Mechanism of action and resistance. In: Fungicide Resistance in North America. C. J. Delp, ed. The American Phytopathological Society, St. Paul, MN.

18. Köller, W., Parker, D. M., and Reynolds, K. L. 1991. Baseline sensitivities of Venturia in aequalis to sterol demethylation inhibitors. Plant Dis. 75:726-728.

19. Köller, W., Parker, D. M., Turechek, W. W., and Avila-Adame, C. 2004. A two-phase resistance response of Venturia inaequalis populations to the QoI fungicides kresoxim-methyl and trifloxystrobin. Plant Dis. 88:537-544.

20. Köller, W., and Scheinpflug, H. 1987. Fungal resistance to sterol biosynthesis inhibitors: a new challenge. Plant Dis. 71:1066-1074.

21. Köller, W., and Wilcox, W. F. 2000. Interactive effects of dodine and the DMI fungicide fenarimol in the control of apple scab. Plant Dis. 84:863-870.

22. Köller, W., and Wilcox, W. F. 2001. Evidence for the predisposition of fungicide-resistant isolates of Venturia inaequalis to a preferential selection for resistance to other fungicides. Phytopathology 91:776-781.

23. Köller, W., Wilcox, W. F., Barnard, J., Jones, A. L., and Braun, P. G. 1997. Detection and quantification of resistance of Venturia inaequalis populations to sterol demethylation inhibitors. Phytopathology 87:184-190.

24. Kunz, S., Deising, H., and Mendgen, K. 1997. Acquisition of resistance to sterol demethylation inhibitors by populations of Venturia in aequalis. Phytopathology 87:1272-1278.

25. Meszka, B., and Bielenin, A. 2001. Decrease of Venturia inaequalis (Cook) Aderh. Sensitivity to ergosterol biosynthesis inhibitor and dodine fungicides. J. Fruit Ornamental Plant Res. 9:86-92.

26. Nakaune, R., Adachi, K., Nawata, O., Tomiyama, M., Akutsu, K., and Hibi, T. 1998. A novel ATP-binding cassette transporter involved in multidrug resistance in the phytopathogenic fungus Penicillium digitatum. Appl. Environ. Microbiol. 64:3983-3988.

27. Olaya, G., and Köller, W. 1999. Baseline 
Sensitivities of Venturia inaequalis populations to the strobilurin fungicide kresoxim-methyl. Plant Dis. 83:274-278.

28. Olaya, G., and Köller, W. 1999. Diversity of kresoxim-methyl sensitivities in baseline populations of Venturia inaequalis. Pestic. Sci. 55:1083-1088

29. Olaya, G., Zheng, D., and Köller, W. 1998. Differential responses of germinating Venturia inaequalis conidia to kresoxim-methyl. Pestic. Sci. 54:230-236.

30. Parisi, L., Guillaumès, J., and Wuster, G. 1994. Variabilité de la sensibilité au fénarimol de souches de Venturia inaequalis provenant de vergers français. Agronomie 14:387-394.

31. Pasche, J. S., and Wharam, C. M. 2004. Shift in sensitivity of Alternaria solani in response to $\mathrm{Q}$ I fungicides. Plant Dis. 88:181-187.

32. Scheinpflug, H., and Kuck, K. H. 1987. Sterol biosynthesis inhibiting piperazine, pyridine, pyrimidine and azole fungicides. In: Modern Selective Fungicides-Properties, Applications and Mechanisms of Action. H. Lyr, ed. John Wiley \& Sons, Inc., New York.

33. Schnabel, G., and Jones, A. L. 2001. The $14 \alpha-$ demethylase (CYP51A1) gene is overexpressed in Venturia inaequalis strains resistant to my- clobutanil. Phytopathology 91:102-110.

34. Shirane, N., Takenaka, H., Ueda, K., Hashimoto, Y., Katoh, K., and Ishii, H. 1996. Sterol analysis of DMI-Resistant and sensitive strains of Venturia inaequalis. Phytochemistry 41:1301-1308.

35. Sholberg, P. L., and Haag, P. D. 1993. Sensitivity of Venturia inaequalis isolates from British Columbia to flusilazole and myclobutanil. Can. J. Plant Pathol. 15:102-106.

36. Smith, F. D., and Koller, W. 1990. The expression of resistance of Ustilago avenae to the sterol demethylation inhibitor triadimenol is an induced response. Phytopathology 80:584-590.

37. Smith, F. D., Parker, D. M., and Köller, W. 1991. Sensitivity distribution of Venturia inaequalis to the sterol demethylation inhibitor flusilazole: baseline sensitivity and implications for resistance monitoring. Phytopathology 81:392-396.

38. Stanis, V. F., and Jones, A. L. 1985. Reduced sensitivity to sterol-inhibiting fungicides in field isolates of Venturia inaequalis. Phytopathology 75:1098-1101.

39. Steinfeld, U., Sierotzki, H., Parisi, S., Poirey, S., and Gisi, U. 2001. Sensitivity of mitochondrial respiration to different inhibitors in Venturia in- aequalis. Pest Manage. Sci. 57:787-796.

40. Von Jagow, G. V., and Link, T. A. 1986. Use of specific inhibitors on the mitochondrial $b c_{1}$ complex. Methods Enzymol. 126:253-271.

41. Wong, F. P., and Wilcox, W. F. 2002. Sensitivity to azoxystrobin among isolates of Uncinula necator: baseline distribution and relationship to myclobutanil sensitivity. Plant Dis. 86:394 404.

42. Wood, P. M., and Hollomon, D. W. 2003. A critical evaluation of the role of alternative oxidase in the performance of strobilurin and related fungicides acting at the Qo site of complex III. Pest Manage. Sci. 59:499-511.

43. Ypema, H. L., and Gold, R. E. 1999 Kresoxim-methyl: modification of a naturally occurring compound to produce a new fungicide. Plant Dis. 83:4-19.

44. Zheng, D., Olaya, G., and Köller, W. 2000 Characterization of laboratory mutants of Venturia inaequalis resistant to the strobilurinrelated fungicide kresoxim-methyl. Curr Genet. 38:148-155

45. Ziogas, B. N., Baldwin, B. C., and Young, J. E. 1996. Alternative respiration: a biochemical mechanism of resistance to azoxystrobin (ICIA 5504) in Septoria tritici. Pestic. Sci. 50:28-34. 